\title{
Developing a Text Messaging Risk Reduction Intervention for Methamphetamine-Using MSM: Research Note
}

\author{
Cathy J. Reback ${ }^{*}, 1$, Deborah Ling ${ }^{1}$, Steven Shoptaw ${ }^{2}$ and Jane Rohde ${ }^{3}$ \\ ${ }^{I}$ Friends Research Institute, Inc., USA \\ ${ }^{2}$ Department of Family Medicine, University of California at Los Angeles, USA \\ ${ }^{3}$ Los Angeles County Department of Public Health, Office of AIDS Programs and Policy, USA
}

\begin{abstract}
Men who have sex with men (MSM) who use methamphetamine experience high risks for HIV infection due to sexual transmission behaviors often engaged in when under the influence of methamphetamine. Methamphetamine-using MSM use various forms of information technology (IT) communication such as instant messaging, social networking sites, and websites to facilitate a sexual and/or drug "hook up." Given the acceptability of IT communication in their daily lives, an IT intervention represents an appropriate strategy to reach and intervene with out-of-treatment, methamphetamine-using MSM. The aim of this study was to conduct formative work to develop a text messaging intervention to reduce methamphetamine use and high-risk sexual behaviors among out-of-treatment MSM, which involved conducting focus groups, community partners' meetings, and a pre-test intervention. These activities culminated in the development of a two-week, text-messaging intervention that delivered real-time electronic correspondence based on the behavioral change theories of Social Support Theory, Health Belief Model, and Social Cognitive Theory. The focus groups, community meetings, and pre-test were used to identify the IT communication device, the text messages that best support risk reduction and healthier behavioral choices, and logo, flyer and website development. The input and feedback from the target population and community partners were critical to the successful development of a culturally appropriate intervention. The knowledge gleaned from the formative work of this study will be vitally helpful in designing future IT studies.
\end{abstract}

Keywords: MSM, Methamphetamine, HIV, IT communication, Text messaging.

\section{INTRODUCTION}

Men who have sex with men (MSM) and who are methamphetamine users are at high risk for HIV acquisition and transmission. Studies show that methamphetamine, in particular, functions as a sex drug in gay communities, where it is used to initiate and enhance sexual encounters [1, 2]. Methamphetamine use among MSM is highly associated with commission of sexual risk behaviors [3-8], which are associated with an increased likelihood of being HIVinfected $[9,10]$ or having a sexually transmitted infection $[5$, 11-14]. Moreover, methamphetamine serves to influence higher-risk sexual activities not typically practiced when not using the drug $[2,7]$.

From 2003 through 2007, the estimated number of national HIV/AIDS cases increased among MSM (including MSM who inject drugs) from $46 \%$ to $54 \%[15,16]$ and, in 2007, MSM accounted for an estimated $75 \%$ of national male HIV/AIDS cases [16]. Of all newly diagnosed HIV infections in 2006, i.e., within 12 months, in the United States, the U.S. Centers for Disease Control and Prevention (CDC) estimated that 55\% were among MSM [16]. These recent increases in MSM underscore that this population continues to be at the core of the HIV/AIDS epidemic in the

*Address correspondence to this author at the Friends Research Institute, Inc., 1419 N. La Brea Avenue, Los Angeles, CA 90028, USA; Tel: 323463-1601; Fax: 323-463-0126; E-mail: reback@friendsresearch.org
United States. And, among this population, methamphetamine-using MSM face risks for seroconversion that are between two and four times that of MSM who do not use this drug [9], presumably from engaging in concurrent drug and sexual HIV-risk behaviors [10]. As rates of methamphetamine use continue to be high among urban MSM [17], researchers and providers continue to seek solutions on how to reduce/eliminate high-risk sexual and drug behaviors among out-of-treatment users.

\section{Information Technology Interventions in MSM}

Gay, lesbian and bisexual consumers have been identified as being among the earliest adopters of the Internet and other information technology (IT) communications [18, 19]. The acceptance of and versatility in the use of IT has made this form of communication ideal for intervening with MSM. Capitalizing on the ease in which MSM integrate IT communication into their daily lives, researchers have recently utilized IT as a vehicle of recruitment via the Internet [20], as a means of data collection using interactive web-based questionnaires $[13,19,21-24]$ and to impart HIV/STD information [22, 25, 26]. Public health and medical professionals have used websites and chat forums to facilitate syphilis testing [27], interactively answer questions about HIV/STDs [27-29], and to screen for depressive symptoms [30]. Instant messaging has recently been implemented as an intervention strategy to communicate HIV/STD information and counseling among MSM [31]. 
Therefore, we hypothesized that brief interventions that target reductions in methamphetamine use and concomitant sexual risk behaviors in MSM can be delivered successfully using text messaging.

The report that follows describes outcomes from formative work to assist the development of a brief, realtime, text-messaging intervention to reduce methamphetamine use and high-risk sexual behaviors among out-oftreatment MSM in Los Angeles County. The formative work included focus groups, community partners' meetings, and a pre-test intervention, which served to inform the development of the intervention based on the behavioral change theories of Social Support Theory, Health Belief Model, and Social Cognitive Theory.

\section{METHOD}

This formative research was conducted between October 2006 and September 2008 and consisted of assessment development and computer programming; logo, flyer, website and recruitment materials development; three focus groups; three community partners meetings, the development of 400 pre-written text messages categorized by theoretical model and participant profiles; and the development of a messaging system. The final step prior to the implementation of the pilot study was a pre-test of the two-week textmessaging intervention.

\section{Focus Groups}

Three focus groups were designed to inform the research team in constructing a culturally competent IT intervention. The focus groups consisted of out-of-treatment methamphetamine-using MSM ( $\mathrm{n}=17)$; MSM in treatment either outpatient or residential - for their methamphetamine use $(n=8)$; and former methamphetamine users with a minimum of one-year abstinence from methamphetamine use $(n=3)$. Each focus group lasted approximately $1 \frac{1}{2}$ hours. Focus groups were audiotaped and two sets of notes were taken by two different members of the research team; however, given that the information gathered in the focus groups was used only to direct the development of the intervention, the tapes were not transcribed. Specific questions of interest were: 1) What types of communication technologies are most used by the target population? 2) What types of messages best support risk reduction and healthier behavioral choices? 3) How do members of the target population use the Internet for technology communication? 4) Is a basic text-messaging device acceptable to this population and suitable for this intervention? 5) What are the suggestions for ongoing mapping of high-risk sites? and, 6) What are the suggestions for the development of a culturally appropriate website?

\section{Community Partners Meetings}

Four local community-based organizations (CBOs) who serve the target population agreed to collaborate on the study as community partners. Each community partner organization provides HIV prevention services to MSM; however, three each serve distinct MSM population such as Asian/Pacific Islander or Latino/Hispanic or exclusively
HIV-positive MSM or a specific geographic location. Staff from the community partner organizations work with methamphetamine-using MSM, however their specific positions varied, e.g., counselor, health educator, executive director. During the formative stage of the study, three community partners meetings were held to review a draft of the recruitment materials, website, pre-written text messages, and the baseline and follow-up assessments. During the community partners meetings the following questions were addressed: 1) What local meetings and events are suitable for recruitment? 2) Are the content areas, language, and length of the assessment instruments appropriate for the target population? 3) Are the recruitment flyer and website informative and user friendly? and, 4) What other websites and venues can be added to the planned recruitment sites?

Feedback from the community partners was essential in fine-tuning the text messages developed in the focus groups, suggesting recruitment sites and ensuring that the intervention was culturally responsive. To that end, the community partners determined that staff should upload all appropriate community referrals into each device before being given to a participant.

\section{Intervention Pre-Test}

After all materials were developed, assessments developed, recorded and installed as an Audio Computer Assisted Self-Interview (ACASI) assessment, texting devices purchased, and software installed and programmed, an intervention pre-test was conducted with "near-peer" volunteers $(n=5)$. All pre-test participants were self-reported gay male former methamphetamine users and were asked to role play an active methamphetamine user to participate in the intervention test. The pre-test procedures were exactly the same as the pilot intervention, with the exception of the follow-up assessment and urine tests for recent drug use, and included providing informed consent, prescreen interview, ACASI, a two-week, real-time, text-messaging intervention. Each pre-test participant was given a text-messaging device with a full keyboard to use during the two-week intervention period. The first three participants received a basic two-way pager messaging device and the final two participants received a first-generation text messaging phone device (with telephone capability disabled) and Internet connection.

The pre-test intervention was used to help the research team answer questions in developing practical implementation details for the intervention such as: 1) Are the study forms such as informed consent, screening instrument, and ACASI appropriate and acceptable to this population? 2) Is the basic two-way pager or text-messaging device suitable for an intervention with this population (i.e., Does the device require a constant change of batteries or constant recharging? Will the participants be willing to carry the device with them? Is the device valuable enough that it will be diverted to the street or sold for drugs or money?); 3) Have appropriate limits been placed on conversation length and times of day/night during which participants can communicate with the project staff? 4) What is the most appropriate text messaging management software for this intervention (i.e., allows for instant transmission of texts, 
keeps track of which messages are sent and how many times, allows staff to maintain simultaneous conversations with multiple participants with ease, compatibility with messaging device)? and, 5) Are the 400 pre-written text messages acceptable to the population and can they be seamlessly woven into conversations without seeming artificial or contrived?

In total, 33 individuals and representatives from four (4) community partner organizations participated in the formative stage of the research project.

\section{RESULTS}

\section{Pre-Written Text Messages}

The formative research activities were instrumental in developing specific text messages that were deemed culturally appropriate for this target population. The text messages were developed within the theoretical framework of Social Support Theory, Health Belief Model and Social Cognitive Theory. According to Social Support Theory, social support encompasses instrumental, emotional, and informational assistance provided by members of one's social network [32, 33]. Health Belief Model asserts that individuals' beliefs regarding threats to their health and their beliefs that specific health behaviors can reduce these threats predict their likelihood of engaging in protective health behaviors $[34,35]$. Social Cognitive Theory posits interactive causal relationships among personal determinants, behavior and environmental influences [36, 37]. Effective HIV prevention interventions applying this theory increases individuals' knowledge and awareness of their health risks, guides them in developing self-regulation skills, offers practice and feedback opportunities, and engages social support resources to maintain prevention behavior.

Focus group and pre-test participants were especially helpful in pointing out specific nuances in the messages that would make them "speak" to the population, keep participants engaged in a text-messaging dialogue, and provide health education, risk reduction and/or social support. At the conclusion of the focus groups and intervention pre-test, 400 pre-written text messages were developed and categorized accordingly: Welcome $=14$ messages; Social Support/Informational Support $=70$ messages; Social Support/Emotional Support $=42$ messages; Social Support/Instrumental Support $=18$ messages; Health Belief Model $/$ Health Threat $=50$ messages; Health Belief Model/Health Behaviors to Reduce Threat $=65$ messages; Social Cognitive Theory/Awareness of Health Risks $=52$ messages; Social Cognitive Theory/Self-regulation Skills = 44 messages; Social Cognitive Theory/Self-efficacy $=28$ messages; Post Intervention Follow-up $=17$ messages (see Table 1 for sample messages).

Although some pre-written messages could reflect more than one behavioral change theory, messages were categorized under the dominant theory. For example, in the message, "Get tested 2nite on the Blvd. We're here 4 U" both Informational Support (Get tested 2nite on the Blvd.) and Emotional Support (We're here $4 \mathrm{U}$ ) are provided. However, in this instance, the main objective is to convey information regarding a testing site and, therefore, the message is categorized under Informational Support. Constructing messages within the guidelines of behavioral chance theory enabled the intervention to be guided by evidence-based concepts and, when the full IT intervention is completed, will provide valuable outcome findings on the acceptability of the different theoretically based messages. These messages were categorized by participant profile/behavioral characteristics (e.g., HIV positive, injector) and inputted into an Excel document before the intervention so the research staff could easily cut and paste an appropriate message into instant messaging text boxes on a computer for instant delivery to the text-messaging device.

The research staff were trained on how to identify and deliver the appropriate pre-written messages as well as how to respond and provide social support and health education messages for any related requests for information received from a participant (e.g., hepatitis information, where to receive free dental care, the location of a food line or soup kitchen). Research staff were instructed to memorize the prewritten texts so these messages could be seamlessly incorporated into text conversations.

To measure and assess behavioral change among the participants, the pre-written text messages were categorized according to key constructs in behavioral change theory (i.e., social support theory, health belief model, social cognitive theory) to provide education, social support, and referrals for healthier, prosocial changes regarding methamphetamineand sexual-risk behaviors. In addition, text messages were coded by prospective participants' profiles such as HIV status and risk activities (e.g., online hook-up or patron of commercial sex venues; receptive, insertive or versatile sexual partner) to facilitate appropriate messaging. Therefore, the IT intervention assesses certain factors of behavioral change such as perceived benefits of engaging in protective health behaviors, and is specifically designed to address barriers to practicing such behaviors, and enhancing self-efficacy. Finally, a complete message log was developed, which will tally the number and type of messages used in the intervention to facilitate a comprehensive content analysis of the text conversations in the data analysis phase of this project. ${ }^{1}$.

\section{Messaging Devices}

During the formative stage of the study, the textmessaging devices changed three times. Given that cellular telephones and cellular phone plans vary tremendously it was determined that in order to ensure uniformity in textmessaging capabilities and messaging service and to ensure that each phone was password protected, each participant

\footnotetext{
${ }^{1}$ Research staff were instructed that approximately $20 \%$ of each text messaging conversation could include extemporaneously created messages. Similar to pre-written messages, these messages were to be tracked and logged. These messages were used to address a particular issue the participant might be experiencing, an issue that was not covered in the prewritten messages such as a request for dental care or a concern about homelessness. Additionally, these messages were used to direct a text conversation toward the pre-written messages.
} 
Table 1. Sample of Pre-written Text Message by Behavioral Change Theory

\begin{tabular}{|c|c|c|c|c|c|c|c|}
\hline \multicolumn{3}{|c|}{ Social Support Theory } & \multicolumn{2}{|c|}{ Health Belief Model } & \multicolumn{3}{|c|}{ Social Cognitive Theory } \\
\hline $\begin{array}{l}\text { Informational } \\
\text { Support }\end{array}$ & $\begin{array}{l}\text { Emotional } \\
\text { Support }\end{array}$ & $\begin{array}{l}\text { Instrumental } \\
\text { Support }\end{array}$ & Health Threat & $\begin{array}{l}\text { Health Behaviors } \\
\text { to Reduce Threat }\end{array}$ & $\begin{array}{l}\text { Awareness of } \\
\text { Health Risks }\end{array}$ & $\begin{array}{l}\text { Self-Regulation } \\
\text { Skills }\end{array}$ & Self-Efficacy \\
\hline $\begin{array}{l}\text { There's no such } \\
\text { thing as a good } \\
\text { sore }\end{array}$ & $\begin{array}{l}\text { Comin } \\
\text { down? Go } \\
2 \text { sleep }\end{array}$ & $\begin{array}{l}\text { Need some- } \\
\text { one } 2 \text { talk } 2 ? \\
\text { We're at } \\
\quad 2 \text { nite }\end{array}$ & $\begin{array}{l}\text { Painless sores } \\
\text { are still very } \\
\text { infectious }\end{array}$ & $\begin{array}{c}\text { Stop B4 U rub it } \\
\text { raw }\end{array}$ & $\begin{array}{l}\text { Don't let Tina } \\
\text { take U down }\end{array}$ & $\begin{array}{l}\text { Red flag if he } \\
\text { doesn't want } 2 \\
\text { protect } U\end{array}$ & U have a choice \\
\hline $\begin{array}{l}\text { Stay on top of } \\
\text { UR numbers }\end{array}$ & $\begin{array}{l}\text { Rehydrate } \\
\text { and rest! }\end{array}$ & Testing 2nite@ & $\begin{array}{l}\text { It might not be } \\
\text { a pimple }\end{array}$ & $\begin{array}{l}\text { Keep UR teeth, } \\
\text { don't tweak }\end{array}$ & $\begin{array}{c}\text { R U a bottom? } \\
\text { Get an anal pap } \\
\text { smear to check } \\
4 \mathrm{HPV}\end{array}$ & $\begin{array}{l}\text { Peace of mind is } \\
\text { priceless }\end{array}$ & $\begin{array}{l}\text { Tell UR partners } \\
\text { what U like \& } \\
\text { don't. U can do } \\
\text { it! }\end{array}$ \\
\hline $\begin{array}{l}\text { Mix Viagra \& } \\
\text { Poppers? U may } \\
\text { come and then } \\
\text { go }\end{array}$ & $\begin{array}{l}\text { B clear } \\
\text { about UR } \\
\text { boundaries }\end{array}$ & $\begin{array}{l}\mathrm{HIV}+\text { case } \\
\text { management? } \\
\text { Go } 2\end{array}$ & $\begin{array}{l}\text { His STD is not } \\
\text { as cute as he is }\end{array}$ & $\begin{array}{l}\text { Don't let NE1 tell } \\
\text { U what UR limits } \\
\text { R! }\end{array}$ & $\begin{array}{c}\text { Sharon } \\
\text { Needles? She's } \\
\text { bad news }\end{array}$ & $\begin{array}{l}\text { Getting stuck } \\
\text { behind UR } \\
\text { computer? Take } \\
\text { a walk }\end{array}$ & $\begin{array}{l}\text { Know UR health } \\
\text { info, B informed! }\end{array}$ \\
\hline $\begin{array}{l}\text { Gums bleeding? } \\
\text { Gargle with } \\
\text { peroxide }\end{array}$ & $\begin{array}{l}\text { Don't } \\
\text { compromise } \\
\text { there's } \\
\text { always a } \\
\text { guy in the } \\
\text { next room }\end{array}$ & $\begin{array}{c}\text { Needle } \\
\text { exchange 2nite } \\
\text { @ }\end{array}$ & $\begin{array}{c}\text { R U drippin' } \\
\text { while UR } \\
\text { trippin'? }\end{array}$ & $\begin{array}{l}\text { Get his \#, not his } \\
\text { STD }\end{array}$ & $\begin{array}{c}\text { If UR poz } \\
\text { don't assume } \\
\text { he is }\end{array}$ & $\begin{array}{l}\text { R U havin' } \\
\text { trouble stayin } \\
\text { with UR plan? } \\
\text { We can help }\end{array}$ & $\begin{array}{l}\text { Say } 1^{\text {st }} \text { thing UR } \\
\text { neg \& always use } \\
\text { condoms, like U } \\
\text { did last time. U } \\
\text { can do it! }\end{array}$ \\
\hline
\end{tabular}

would receive a study-provided device, which he could keep after his participation was completed.

The Motorola T900 two-way paging device originally considered for the intervention was the most economical option at $\$ 20$ per unit; however, testing of the device showed multiple deficiencies. The first three pre-test participants indicated that the pager was unacceptable and, particularly given the rapid change in innovative smart-phone technology, they would not be willing to carry this device. A pager also had the following weaknesses as a platform for an IT intervention: 1) The menus were not intuitive, were difficult to understand and involved many steps to access the screens to enter and delete messages; 2) Message transmission was slow, with some delays up to three hours; 3) There were no rechargeable batteries, therefore, disposable batteries were provided by the study and needed to be replaced often, approximately every two days; 4) There was very little memory in the device, which required participants to constantly erase incoming and outgoing messages; and 5) the device was bulky and outdated.

A more advanced device, The first generation T-Mobile Sidekick, at $\$ 40$ per unit, included a flip color screen display, full keyboard, easy to use menus, rechargeable battery, and a fast Internet connection. Still, this device was an early generation product and also showed deficiencies. The device had limited memory capacity, and messages needed to be deleted regularly. The battery life was limited and participants were required to recharge the device nightly. In addition, each device had to be set-up separately with a Subscriber Identity Module (SIM) card and loaded with referrals for participants, with texting service, but no phone service, and without capability to download games, ringtones, or other extras. A few devices had some hardware issues such as loose screens, broken side doors and bay covers, and additional signs of wear and tear such as paint rubbed off the individual keyboard letters.

Finally, a slightly newer generation of the T-Mobile Sidekick that addressed the hardware and internal battery issues were purchased, at $\$ 85$ per unit. There were no hardware, software, or battery issues observed with these devices.

\section{Software to Manage Message Transmission}

The selection of a messaging system software to manage text transmission between the study staff and participants proved to be a challenge. The original system was deemed to be inadequate during the pre-test intervention as the software resided on one computer and all text messages were sent through email messages only. The system was originally chosen as it had the capability of programming the prewritten messages into pull-down menus. However, the system was lacking in its ability to track and tally messages, ensure instant messaging (there was significant delay between transmission and receipt), and allow for multiple staff to manage messaging to and from participants.

Following the pre-test intervention an online system was selected. This system was accessible from any computer with an Internet connection, was economical, allowed for the Study Coordinator to login to the system at any time and monitor conversations, and could easily manage simultaneous conversations from multiple participants at one time. ${ }^{2}$ Finally, the online instant messaging system (AIM) offered by America Online was selected. This system was compatible with the text-messaging devices, was offered for free, could be set-up on any computer with an Internet

\footnotetext{
${ }^{2}$ This system worked for several months, but suddenly, a few weeks after the intervention started, the system no longer displayed texts from participants. The text messaging system was no longer compatible with the devices to be used in this study.
} 
connection, offered good logging of messages with exact timestamp, and provided an easy instant messaging window that was acceptable and familiar to the staff. However, the staff were still required to cut and paste the pre-written texts and keep a daily tally of which messages were transmitted in an Excel document.

\section{Phone/Device Service}

Service lines were purchased separately, each with its own one-year contract; however, the study had to use devices that were compatible with that service only. The study purchased 35 lines at $\$ 30$ each per month and chose a "data only" service contract with unlimited text messaging and Internet service, but without a "voice" plan or phone minutes. ${ }^{3}$

\section{Procedure Refinement}

Additional procedural refinements were made following the intervention pre-test. Given the learning curve for creating texts, responding to texts, and regularly erasing messages a one-page fact sheet with instructions was designed to give to study participants with their device. The pre-test participants also helped to determine the optimal days and times during which the staff would be online to communicate with participants. Finally, it was determined that, to adequately participate in the intervention, all participants needed to have the capability to charge their device daily for eight consecutive hours.

\section{Message Acceptability}

Pre-test participants would either initiate contact or respond to research staff text messages. To maintain consistency between text-messaging correspondences, the upper limit on each "text messaging conversations" was 20 messages sent per party (i.e., 20 messages from the research staff to the participant and 20 messages from the participant to the research staff), or 40 messages total per conversation. The research staff engaged in a maximum of four "text messaging conversations" per day, per participant. Several markers of message acceptability during the pre-test were observed. These included the fact that pre-test participants remarked they could not differentiate between the prewritten messages and the extemporaneous messages. Another marker of acceptability came when a participant confirmed, through the text conversation, that the message(s) written were relevant and important to their current situation. For example, when staff wrote, "U can njoy \& protect urself at the same time," and the participants responded, "Decide not to smk $\mathrm{T}$ went to a friends 4 the nite thnx 4 makn me think bout it." A message was also considered acceptable when a participant continued a text conversation that staff initiated; such as staff wrote, "H20 is UR friend, drink it

\footnotetext{
${ }^{3}$ A voice plan was not activated to maximize the internal validity of a textmessaging intervention. Later, during the implementation stage, a special allowances plan was added, which barred participants from downloading or adding games, ringtones, or other extras that could be charged to the study. This extra plan, which cost $\$ 20$ a month, was added after approximately $\$ 500$ in extra games and services were charged to the study by a few participants.
}

down," and the participant responded, "no T 2nite just weed n didn't have sex with my friend, so I'm safe, thnx."

\section{DISCUSSION}

Many MSM are technology savvy and spend a great deal of time online. Among methamphetamine-using MSM, social networking sites are often used to facilitate a sexual and/or drug "hook up." Therefore, an IT intervention represents an appropriate way to reach out-of-treatment, methamphetamine-using MSM in real time, when they are most likely to need social support, reminders of risk reduction behaviors and referrals. The IT intervention capitalizes on using a communication channel to which this population will attend and to do so at the exact time when they are most likely to make high-risk sexual and substance use decisions.

During the formative stage it was critical to incorporate input from the target population and community partners for the successful development of a culturally appropriate IT intervention. Critical changes were made and new strategies implemented as a result of the focus groups and community partners' meetings. Through this process there were several lessons learned regarding the operational procedures of an IT intervention, the budgetary constraints, and matching the participants' desire for a certain cellular phone with those of the study's need. Specifically, is it possible or preferable for participants to use their own cell phones or texting devices? Other studies have taken this route, but it requires that the participants opt-in to receive specific content from the program. Opting-in requires the participant to text a five-tosix letter/digit code which enables their personal cellular phone to receive and send messages through a particular service. Also, the content materials used in these IT interventions are often pre-written and menu-driven rather than real-time communication. Thus, these interventions are unilateral rather than open text conversations. Purchasing the device and service plan together allows for consistency in cellular phones and plans. This is especially useful when working with out-of-treatment substance users as it is then difficult to ensure participants will keep their phone service active throughout the duration of the study. And, is it possible to subcontract a software programmer to build a custom messaging system for in-house use? Ideally, a programmer is identified and incorporated into the budget during the grant development process. It can be extremely useful for a system to customize the study's preferences and needs, and compatibility is then ensured; however, it can also be quite expensive.

One challenge in using the latest technological resources and channels in a research study is that the length of time it takes to obtain protocol approval and start recruitment for the study will often exceed the rate of technological advancement. For example, when this study was designed, the messaging device considered for use was a 2-way pager. However, by the time the study was implemented, a 2-way pager was considered grossly obsolete and research budgets do not always allow studies to keep up with the speed of the technology. 
An IT intervention using text-messaging, social networking sites or a combination of IT communication options is an innovative and feasible way to reach and intervene with out-of-treatment, methamphetamine-using MSM. The knowledge garnered from the formative stage of this IT intervention study can be helpful when designing future studies. It is likely; however, that the devices, messaging systems, software, and Internet access protocols will continue to change more rapidly than the rate with which research studies can be implemented. Given ongoing technology advances it will be critical to be flexible and to glean the lessons that can inform the development of future IT studies.

\section{ACKNOWLEDGEMENTS}

This study was generously supported by the Centers for Disease Control and Prevention, grant \# UR6PS000312. The research team would like to thank the focus group and pretest participants and our community partners - Asian Pacific AIDS Intervention Team, Being Alive, Los Angeles Gay and Lesbian Center, and The Wall/Las Memorias - for their participation in the formative work of the study. We would also like to thank our colleagues at CDC, Mahnaz Charania and Gordon Mansergh, for their guidance and collaboration.

\section{REFERENCES}

[1] Halkitis PN, Parsons JT, Stirratt MJ. A double epidemic: crystal methamphetamine drug use in relation to HIV transmission among gay men. J Homosex 2001; 41: 17-35.

[2] Reback CJ. The social construction of a gay drug: Methamphetamine use among gay and bisexual males in Los Angeles. Los Angeles: City of Los Angeles, AIDS Coordinator's Office 1997.

[3] Colfax GN, Mansergh G, Guzman R, et al. Drug use and sexual risk behavior among gay and bisexual men who attend circuit parties: A venue-based comparison. J Acquir Immune Defic Syndr 2001; 28: 373-9.

[4] Mansergh G, Colfax G, Marks G, Rader M, Guzman R, Buchbinder S. The Circuit Party Men's Health Survey: Findings and implications for gay and bisexual men. Am J Public Health 2001; 91: 953-8.

[5] Molitor F, Traux SR, Ruiz JD, Sun RK. Association of methamphetamine use during sex with risky sexual behaviors and HIV infection among non-injection drug users. West J Med 1998; 168: 93-97.

[6] Purcell DW, Parsons JT, Halkitis PN, Mizuno Y, Woods WJ. Substance use and sexual transmission risk behavior of HIVpositive men who have sex with men. J Subst Abuse 2001; 13: 185200.

[7] Reback CJ, Larkins S, Shoptaw S. Changes in the meaning of sexual risk behaviors among gay and bisexual male methamphetamine abusers before and after drug treatment. AIDS Behav 2004; 8: 87-98.

[8] Shoptaw S, Reback CJ, Frosch DL, Rawson RA. Stimulant abuse treatment as HIV prevention. J Addict Dis 1998; 17: 19-32.

[9] Plankey MW, Ostrow DG, Stall R, et al. The relationship between methamphetamine and popper use and risk of HIV seroconversion in the multicenter AIDS cohort study. J Acquir Immune Defic Syndr 2007; 45: 88-92.

[10] Shoptaw S, Reback CJ. Associations between methamphetamine use and HIV among men who have sex with men: A model for guiding public policy. J Urban Health: Bulletin of the New York Academy of Medicine, 2006; doi: 10.1007/s11524-006-9119-5.

[11] Greenwood GL, White E, Page-Shafer K, et al. Correlates of heavy substance use among young gay and bisexual men: The San Francisco Young Men's Health Study. Drug Alcohol Depend 2000; 61: 105-12.
[12] Stall R, Paul JP, Greenwood G, et al. Alcohol use, drug use and alcohol related problems among men who have sex with men: the Urban Men's Health Study. Addiction 2001; 96: 1589-601.

[13] Hirshfield S, Remien RH, Walavalkar I, Chiasson MA. Crystal methamphetamine use predicts incident STD infection among men who have sex with men recruited online: a nested case-control study. J Med Internet Res 2004; 6: 41.

[14] Wong W, Chaw JK, Kent CK, Klausner JD. Risk factors for early syphilis among gay and bisexual men seen in an STD clinic: San Francisco, 2002-2003. Sex Transm Dis 2005; 32: 458-463.

[15] Centers for Disease Control and Prevention. HIV/AIDS Surveillance Report, 2006. Vol. 18. Rev ed. Atlanta, GA: US Department of Health and Human Services, CDC: 2008: 11. Available at: http: //www.cdc.gov/hiv/topics/surveillance/resources/ reports/. [Accessed September 30, 2009]

[16] Centers for Disease Control and Prevention. (2009). HIV/AIDS Surveillance Report, 2007. Vol. 19. Rev ed. Atlanta, GA: US Department of Health and Human Services, CDC: 2009: 12, 14. Available at http: //www.cdc.gov/hiv/topics/surveillance/resources/ reports/. [Accessed November 2, 2009]

[17] Reback CJ, Shoptaw S, Grella CE. Methamphetamine use trends among street-recruited gay and bisexual males, from 1999 to 2007. J Urban Health 2008; 85(6): 874-9.

[18] Wong N, Gullo K, Stafford, J. Gays lead non-gays in cell phone use, cable TV and HDTV viewership. Technology use and preferences of gay and non-gay consumers. 2004; www.harris interactive. com. [Accessed September 21, 2009].

[19] Bolding G, Davis M, Sherr L, Hart G, Elford, J. Use of gay Internet sites and views of online health promotion among men who have sex with men. AIDS Care 2004; 16: 993-1001.

[20] Davis M, Bolding G, Hart G, Sherr L, Elford J. Reflecting on the experience of interviewing online: Perspectives from the Internet and HIV study in London. AIDS Care 2004; 16: 955-52.

[21] McFarlane M, Kachur R, Klausner JD, Roland E, Cohen M. Internet-based health promotion and disease control in the 8 cities: Successes, barriers, and future plans. Sex Transm Dis 2005; 32: S60-4.

[22] Bull SS, McFarlane M, King D. Barriers to STD/HIV Prevention on the Internet. Health Educ Res 2001; 16: 661-70.

[23] Elford J, Bolding G, Davis M, Sherr L, Hart, G. The internet and HIV study: Design and methods. Bio Med Central Public Health 2004; 4: 39. Available at: http: //www.biomedcentral.com/14712458/4/39. [Accessed September 21, 2009]

[24] Tikkanen R, Ross MW. Technological tearoom trade: Characteristics of Swedish men visiting gay internet chat rooms. AIDS Educ Prev 2003; 15: 122-32.

[25] Chiasson MA, Parsons JT, Tesoriero JM, Carballo-Dieguez A, Hirshfield S, Remien RH. HIV behavioral research online. J Urban Health 2006; 83: 73-85.

[26] Levine D, McCright J, Dobkin L, Woodruff AJ, Klausner JD. SEXINFO: a sexual health text messaging service for San Francisco youth. Am J Public Health 2008; 98: 393-5.

[27] Klausner JD, Kent CK, Wong W, McCright J, Katz MH. The public health response to epidemic syphilis, San Francisco, 1999 2004. Sex Transm Dis 2005; 32: S11-8.

[28] Klausner JD, Levine DK, Kent CK. Internet-based site-specific interventions for syphilis prevention among gay and bisexual men. AIDS Care 2004; 16: 964-70.

[29] Bowen AM, Williams ML, Daniel CM, Clayton S. Internet based HIV prevention research targeting rural MSM: feasibility, acceptability, and preliminary efficacy. J Behav Med 2008; 31: 463-77.

[30] Hirshfield S, Wolitski RJ, Chiasson MA, Remien RH, Humberstone M, Wong T. Screening for depressive symptoms in an online sample of men who have sex with men. AIDS Care 2008; 20: 904-10.

[31] Moskowitz DA, Melton D, Owczarzak J. PowerON: the use of instant message counseling and Internet to facilitate HIV/STD education and prevention. Patient Educ Couns 2009; 77: 20-6.

[32] Cohen S, Herbert TB. Psychological factors and physical disease from the perspective of human psychoneuroimmunology. Annu Rev Psychol 1996; 47: 113-42.

[33] Derlega VJ, Winstead BA, Oldfield EC, Barbee AP. Close relationships and social support in coping with HIV: a test of sensitive interaction systems theory. AIDS Behav 2003; 7: 119-29. 
[34] Rosenstock IM. Why people use health services. Milbank Mem Fund Q 1966; 44(S): 94-127.

[35] Janz NK, Becker MH. The health belief model: a decade later. Health Educ Q 1984; 11: 1-47.
[36] Bandura A. The anatomy of stages of change. Am J Health Promot 1997; 12: 8-10.

[37] Bandura A. Health promotion by social cognitive means. Health Educ Behav 2004; 31: 143-64.

(C) Reback et al.; Licensee Bentham Open.

This is an open access article licensed under the terms of the Creative Commons Attribution Non-Commercial License (http://creativecommons.org/licenses/by-nc/

3.0/) which permits unrestricted, non-commercial use, distribution and reproduction in any medium, provided the work is properly cited. 